\title{
Congenital cataract- a riddle to be solved to prevent childhood blindness
}

\author{
Verma A. ${ }^{1}$, Jain P. ${ }^{2}$ \\ ${ }^{1}$ Dr. Abha Verma, Associate Professor, ${ }^{2}$ Dr. Pragati Jain, Post Graduate Student; both authors are affiliated with Sri \\ Aurobindo Medical College and PG Institute, Indore (M.P.), India.
}

Corresponding Author: Dr. Abha Verma, Associate Professor, Sri Aurobindo Medical College and PG Institute, Indore (M.P.), India.

\begin{abstract}
Introduction: Congenital cataract is a significant cause of visual disability in developing countries. It may present at birth or develop within first year of life. Common causes are genetic disorders, intra uterine infections, drug induced and others. Hence management protocol depends from case to case. Timely management of cataract and rehabilitation significantly prevents visual morbidity in children. Aims and Objectives: To asses visual outcomes in congenital cataract. Material and Methods: A prospective study was done from January 2017 to July 2018, including 40 patients with age ranging from 1 month to 12 years. Detailed history and thorough examination of each patient was done. After fulfilling inclusion criteria we have planned them for small incision cataract surgery (SICS) and phacoemulsification as per the financial status of family. Only cases less than 1 year were left aphakic. IOL power was calculated using SRK-II formula. Post operative visual acuity was noted on $7^{\text {th }}$ day, $15^{\text {th }}$ day and 1 month. Visual rehabilitation in the form of amblyopia therapy, secondary IOL and contact lenses was given. Result: It was found that squint (20\%) and amblyopia $(17.5 \%)$ was associated with cataract. All 40 eyes underwent cataract extraction by phacoemulsification (60\%) and SICS (40\%). Among them 25\% cases were left aphakic. Visual improvement was almost similar in both surgeries. Visual rehabilitation in the form of spectacles (45\%), contact lenses $(5 \%)$, occlusion therapy (17.5\%) and secondary IOL $(22.5 \%)$ were given. Conclusion: Proper counseling of parents at diagnosis helps in prompt management and improves compliance which significantly reduces visual morbidity in children.
\end{abstract}

Key words- Congenital cataract, Visual outcome, Visual rehabilitation

\section{Introduction}

Pediatric cataract is one of the major causes of preventable childhood blindness, affecting approximately 200,000 children worldwide, with an estimated prevalence ranging from three to six per 10,000 live births [1-3]. Pediatric cataracts may be congenital if present within the first year of life, developmental if present after infancy, or traumatic.

Common causes are genetic disorders, intra uterine infections, drug induced and others. Early diagnosis and treatment are of crucial importance to prevent the development of irreversible stimulus deprivation amblyopia. The management of pediatric cataract should be customized depending upon the age of onset, laterality, morphology of the cataract, and other associated ocular and systemic co-morbidities.

Manuscript received: $2^{\text {nd }}$ December 2018

Reviewed: $11^{\text {th }}$ December 2018

Author Corrected: $16^{\text {th }}$ December 2018

Accepted for Publication: $19^{\text {th }}$ December 2018
Despite developments in surgical techniques and intraocular lenses, the management of unilateral pediatric cataracts is still clinically challenging. Better visual outcomes are usually obtained with early surgical correction and vigorous amblyopia treatment $[4,5,6,7]$. Visual system is developed in children as long as sharp, clear and focused images are formed on the retina of both eyes. Otherwise, amblyopia is observed. Therefore, early detection and surgery as well as follow-up visits have significant roles in the restoration of a child's vision in the case of congenital cataract with significant media opacity [8].

Unfortunately, in many cases, even after early surgery, long-term follow-up (at least up to the age of 10) is not properly instituted, and varying degrees of amblyopia have been reported despite wearing appropriate eye glasses, contact lenses, or implantation of intra ocular lenses (IOL) [9]. 
The first years of life are crucial for the development of a child's vision and therefore irreversible amblyopia can be induced by blurred and distorted retinal image over that period $[10,11]$.

\section{Material and Methods}

Study Design- Prospective interventional study

Sample Size and Duration- A prospective interventional study was done from January 2017 to July 2018 , including 40 patients upto 12 years of age.

There was a programme going on by government RBSK (Rashtriya Bal Swasthya Karyakram) to prevent childhood blindness, so we have taken 24 patients out of 40 from this programme.

Methodology- The following clinical variables were analysed: patient's gender, age at diagnosis, presenting symptoms, laterality, morphology, aetiology, presence of other ocular and systemic abnormalities, family history of cataract, follow up time and treatment.

In case of surgery, the following parameters were assessed: age at surgery, time from diagnosis to surgery, intra and postoperative complications and pre and postoperative visual acuity.

Detailed history and thorough examination of each patient was done.

\section{Ocular Examination-}

1. Visual acuity and best corrected visual acuity (by preferential looking behaviour in younger (upto 3 year) and Snellen's chart in older children (above 3 year).

2. Slit lamp bio microscopy by $90 \mathrm{D}$ or $78 \mathrm{D}$ lens

3. Fundus Examination- by direct ophthalmoscopy and indirect ophthalmoscopy using 20D lens.

4. B- Scan ultrasonography - to evaluate posterior segment pathology

\section{Results}

Table-1: Demographic profile.

\begin{tabular}{|c|c|c|c|}
\hline S. No. & Sex & Number of patients & $\%$ \\
\hline 1. & Male & 20 & $(50 \%)$ \\
\hline 2. & Female & 20 & $(50 \%)$ \\
\hline
\end{tabular}

In our study equal sex distribution was observed.
5. Biometry- IOL power was calculated using SRK-II formula.

Keratometry was done using bousch and lomb automated keratometer under general anaesthesia.

Axial length of eye using A-scan

6. Examination under anaesthesia (if required)

- Intra ocular pressure by Sciotz tonometry

- Syringing for patency of lacrimal apparatus.

All routine pre operative blood investigations were sent along with TORCH (Toxoplasma, rubella, cytomegalo virus, herpes virus) profile of mothers and children. Post operative ocular examination and visual acuity was noted on $7^{\text {th }}$ day, $15^{\text {th }}$ day and 1 month.

Visual rehabilitation in the form of amblyopia therapy, secondary IOL and contact lenses was given accordingly.

\section{Inclusion Criteria}

- Patients aged less than 12 years.

- Parents who are willing to follow up

\section{Exclusion Criteria}

Children with associated ocular condition like

- Traumatic cataract

- Retinopathy of prematurity

- Microphthalmos

- Persistent fetal vasculature

- Children with other systemic diseases like Marfan syndrome, Lowe's syndrome, Galactosemia, Hypothyroidism and those with learning disability were also excluded.

After fulfilling inclusion criteria we have planned them for small incision cataract surgery (SICS) and phacoemulsification as per the financial status of family. 
Table-2 Demographic profile.

\begin{tabular}{|c|c|c|c|}
\hline S. No & Age group & Number of patients & \% \\
\hline 1. & $<1$ Year & 10 & $25 \%$ \\
\hline 2. & $1-5$ Years & 10 & $50 \%$ \\
\hline 3. & $>5$ Years & 20 & $50 \%$ \\
\hline
\end{tabular}

In our study $50 \%$ patients were age group more than 5 year.

Table-3 Type of surgery

\begin{tabular}{|c|l|c|c|}
\hline Serial No. & \multicolumn{1}{|c|}{ Procedure } & Number of patients & $\%$ \\
\hline 1. & SICS with PCIOL & 12 & $30 \%$ \\
\hline 2. & SICS + Anterior Vitrectomy & 4 & $10 \%$ \\
\hline 3. & Phacoemulsification with PCIOL & 18 & $45 \%$ \\
\hline 4. & Phacoemulsification + Anterior Vitrectomy & 6 & $15 \%$ \\
\hline
\end{tabular}

In our study $60 \%$ cases were of phacoemulsification (PCIOL/Anterior vitrectomy)

Table-4: Pseudophakic/Aphakic.

\begin{tabular}{|c|c|c|}
\hline Procedure & Number of patients & $\%$ \\
\hline PCIOL Implanted & 30 & $75 \%$ \\
\hline Aphakia & 10 & $25 \%$ \\
\hline
\end{tabular}

In our study PCIOL is implanted in most of the cases.

Table-5: Laterality.

\begin{tabular}{|c|c|c|}
\hline Sex & Children with Bilateral presentation & Children with unilateral presentation \\
\hline Male & $14(35 \%)$ & $6(15 \%)$ \\
\hline Female & $12(30 \%)$ & $8(20 \%)$ \\
\hline Total & $\mathbf{2 6}$ & $\mathbf{1 4}$ \\
\hline
\end{tabular}

In our study bilateral presentation were more common.

Table-6: Pre-operative visual acuity according to age group.

\begin{tabular}{|c|c|c|c|c|c|c|}
\hline \multirow{2}{*}{ Visual Acuity } & \multicolumn{7}{|c|}{ Age } \\
\cline { 2 - 7 } & $<\mathbf{1 ~ Y e a r ~}$ & $\%$ & $\mathbf{1 - 5}$ Years & \% & $>\mathbf{5}$ Years & $\%$ \\
\hline Uncooperative & 6 & $15 \%$ & 2 & $5 \%$ & 0 & 0 \\
\hline FL TO CF & 4 & $10 \%$ & 4 & $10 \%$ & 8 & $20 \%$ \\
\hline $1 / 60-6 / 60$ & 0 & 0 & 3 & $7.5 \%$ & 6 & $15 \%$ \\
\hline$>6 / 60$ & 0 & 0 & 1 & $2.5 \%$ & 6 & $15 \%$ \\
\hline Total & $\mathbf{1 0}$ & & $\mathbf{1 0}$ & & $\mathbf{2 0}$ & \\
\hline
\end{tabular}

Pre operative visual acuity were Following light to counting fingers in most of the cases. 
Table-7: Post operative best corrected visual acuity at 1 month

\begin{tabular}{|c|c|c|c|c|c|c|}
\hline \multirow[t]{2}{*}{ Visual Acuity } & \multicolumn{6}{|c|}{ Age } \\
\hline & $<1$ Year & $\%$ & 1-5 Year & $\%$ & $>5$ Year & $\%$ \\
\hline Uncooperative & 2 & $5 \%$ & 0 & 0 & 0 & 0 \\
\hline FL TO CF & 8 & $20 \%$ & 1 & $2.5 \%$ & 2 & $5 \%$ \\
\hline $1 / 60-6 / 60$ & 0 & 0 & 5 & $12.5 \%$ & 8 & $20 \%$ \\
\hline$>6 / 60$ & 0 & 0 & 4 & $10 \%$ & 10 & $25 \%$ \\
\hline Total & 10 & & 10 & & 20 & \\
\hline
\end{tabular}

Post operative visual acuity was improved to more than $6 / 60$

Table-8: Fundus evaluation in operated cases

\begin{tabular}{|c|c|}
\hline Fundus Appearance & Number of patients \\
\hline Salt \& pepper retinopathy & 6 \\
\hline Myopic fundus & 5 \\
\hline Normal & 29 \\
\hline
\end{tabular}

In our study, normal fundus were found in most of the cases

Table-9: Type of cataract

\begin{tabular}{|c|c|}
\hline Type of Cataract & Number of patients \\
\hline Lamellar cataract & 5 \\
\hline Zonular cataract & 7 \\
\hline Membranous cataract & 28 \\
\hline
\end{tabular}

We have found that 5 children came positive for TORCH infections.

Among them one was positive for Rubella (Titre >1.1) and other 4 were positive for both Rubella as well as cytomegalovirus (Titre $>1.1$ ).

Visual Rehabilitation- Visual rehabilitation was given in the form of spectacles, contact lenses, secondary IOL, occlusion therapy. Spectacles were the most commonly prescribed mode of visual rehabilitation followed by contact lenses

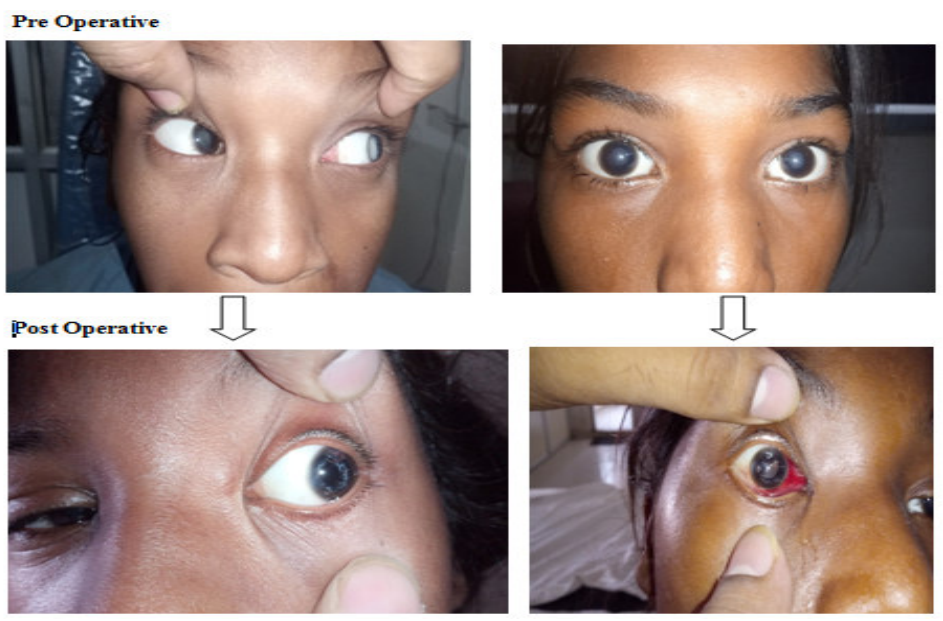




\section{Discussion}

In the present study, the clinical and surgical data of 40 patients with congenital cataract were taken. The youngest child in this study was 1 month old and eldest was 12 years old.

Most of the cases in our study were operated at more than 5 year of age while in the studies of the UK $[12,13]$ China [14] Ethiopia [15] and Kuwait [16] the children were operated at the mean age of 12 months, 8.7 weeks, 5.6 months, 7.21 years, and 12 months, respectively.

Our mean age of surgery was closer to the results from Ethiopia than other countries. Based on the above reports, it should be noted that the diagnosis and surgery of congenital cataract were unfortunately more delayed in some developing countries compared to developed countries. The reason could be due to late diagnosis and therefore late surgery, less severity or peripheral lens opacity with acceptable visual acuity, unavailable subspecialty of pediatric ophthalmologist in the rural regions, poor economic status, or a combination of some the above mentioned etiologies.

The postoperative visual acuity results of $25 \%$ of patients having $\mathrm{BCVA} \geq 6 / 60$ compare favourably with reports from Central India [17] Tanzania [18] and Nepal [19]. There were 26 patients $(65 \%)$ with bilateral and $14(35 \%)$ with unilateral congenital cataract. Lee and Msamati et al. also reported more bilateral cases in their studies [20,21].

Compared with previous studies from developed countries $[22,23,24]$ delay of surgery in this study was still very common because most of our patients came from rural areas where there was a poor primary eye care system. The preoperative visual acuity ranged from perception of light to 6/36. After surgery, 32.5\% (13 eyes) had $1 / 60$ to $6 / 60$ vision, $35 \%$ (14 eyes) had $>6 / 60$ vision. The rest $27.5 \%$ (11 eyes) had perception of light to finger counting vision.

\section{Conclusion}

The generally accepted minimum age of IOL implantation in pediatric cataracts is $1-2$ years. For $<1$ year old IOL implantation is still controversial. The basic concept is to leave them more hyperopic the younger they are to compensate for the myopic shift. Refined surgical techniques with posterior CCC, anterior vitrectomy, in-the-bag IOL implantation with/without IOL capture helps to reduce incidence of PCO.
Early diagnosis and prompt surgical intervention are extremely important in the management of paediatric cataract, as also adequate visual rehabilitation in the form of spectacles with both distance and near correction. The parents need to be counselled about the importance of postoperative care, follow-up, refraction and compliance of spectacle wear [25]. In our study surgery was performed by single surgeon (unit head) with preoperative and post operative examination. Data collection and manuscript work was done by resident under consultant supervision and guidance.

What this study adds to existing knowledge- Our study emphasize the importance of programmes held by government to prevent childhood blindness so that we could get more number of children in this short period of time. Surgery is only one aspect of the entire management of pediatric cataract patient. Participation in the visual rehabilitation of the child involving parents, ophthalmologists, paediatricians and optometrists need not be over emphasized.

Funding: Nil, Conflict of interest: Nil

Permission from IRB: Yes

\section{References}

1. Foster A, Gilbert C, Rahi J. Epidemiology of cataract in childhood: a global perspective. J Cataract Refract Surg. 1997;23 Suppl 1:601-4.

2. Gibbs ML, Jacobs M, Wilkie AO, et al. Posterior lenticonus: clinical patterns and genetics.J Pediatr Ophthalmol Strabismus. 1993 May-Jun;30(3):171-5.

3. Francis PJ, Moore AT. Genetics of childhood cataract. Curr Opin Ophthalmol. 2004 Feb;15(1):10-5.

4. Lin H, Yang Y, Chen J, et al. Congenital cataract: prevalence and surgery age at Zhongshan Ophthalmic Center (ZOC). PLoS One. 2014;9:e101781.

5. Drummond GT, Scott WE, Keech RV. Management of monocular congenital cataracts. Arch Ophthalmol. 1989 Jan;107(1):45-51.

6. Birch EE, Stager DR. The critical period for surgical treatment of dense congenital unilateral cataract. Invest Ophthalmol Vis Sci. 1996 Jul;37(8):1532-8.

7. Lundvall A, Kugelberg U. Outcome after treatment of congenital unilateral cataract. Acta Ophthalmol Scand. 2002 Dec;80(6):588-92. 
8. World Health Organization Preventing Blindness in Children; 2000

9. Birch EE, Wang J, Felius J, Stager Jr DR, Hertle RW. Fixation control and eye alignment in children treated for dense congenital or developmental cataracts. J AAPOS. 2012;16:156e160

10. Elston JS, Timms C. Clinical evidence for the onset of the sensitive period in infancy. Br J Ophthalmol. 1992 Jun;76(6):327-8.

11. Birch EE, Cheng C, Stager DR Jr, et al. The critical period for surgical treatment of dense congenital bilateral cataracts. J AAPOS. 2009 Feb; 13(1):67-71. doi: 10.1016/j.jaapos.2008.07.010. Epub 2008 Dec 12.

12. Chak M, Wade A, Rahi JS; et al. Long-term visual acuity and its predictors after surgery for congenital cataract: findings of the British congenital cataract study. Invest Ophthalmol Vis Sci. 2006 Oct;47(10): 4262-9. DOI:10.1167/iovs.05-1160

13. Jain S, Ashworth J, Biswas S, et al. Duration of form deprivation and visual outcome in infants with bilateral congenital cataracts. J AAPOS. 2010 Feb;14 (1): 31-4. doi: 10.1016/j.jaapos.2009.11.016.

14. Eriksen JR, Bronsard A, Mosha M, Carmichael D, Hall A, Courtright P. Predictors of poor follow-up in children that had cataract surgery. Ophthalmic Epidemiol. 2006;13:237e243

15. Tomkins O, Ben-Zion I, Moore DB, et al. Outcomes of pediatric cataract surgery at a tertiary care center in rural southern Ethiopia. Arch Ophthalmol. 2011 Oct; 129(10):1293-7 doi:10.1001/archophthalmol. 2011. 268

16. Abdelmoaty SM, Behbehani AH. The outcome of congenital cataract surgery in Kuwait. Saudi J Ophthalmol. 2011 Jul;25(3):295-9. doi: 10.1016/j.sjopt. 2011. 01.002. Epub 2011 Jan 14.
17. Khandekar $\mathrm{R}^{1}$, Sudhan A, Jain BK, et al. Pediatric cataract and surgery outcomes in Central India: a hospital based study. Indian J Med Sci. 2007 Jan;61 (1): 15-22.

18. Eriksen JR, Bronsard A, Mosha M, Carmichael D, Hall A, Courtright P. Predictors of poor follow-up in children that had cataract surgery. Ophthalmic Epidemiol 2006;13:237-43.

19. Thakur J, Reddy H, Wilson ME Jr, et al. Pediatric cataract surgery in Nepal. J Cataract Refract Surg. 2004 Aug; 30 (8):1629-35. DOI:10.1016/j.jcrs.2003.12.047

20. Lee YC, Kim HS. Clinical symptoms and visual outcome in patients with presumed congenital cataract. J Pediatr Ophthalmol Strabismus. 2000;37:219e224.

21. Msamati BC, Igbigbi PS, Batumba NH. Prevalence of lens opacity at Queen Elizabeth Central Hospital in Blantyre, Malawi. East Afr Med J. 2000 Nov;77(11): 583-7.

22. Birch EE, Stager DR. The critical period for surgical treatment of dense congenital unilateral cataract. Invest Ophthalmol Vis Sci. 1996 Jul;37(8):1532-8.

23. Sjoestrand J, Magnusson G, Nystroem A, Jonsson R. Stability of visual outcome from 7 years in children treated surgically for bilateral dense congenital cataracts before 37 weeks of age. Acta Ophthalmol (Copenh) 2011; 89 (1):30-6.

24. Birch EE, Wang J, Felius J, et al. Fixation control and eye alignment in children treated for dense congenital or developmental cataracts. J AAPOS. 2012 Apr;16(2):156-60. doi: 10.1016/j.jaapos.2011.11.007.

25. Jitendra Kumar, Aakanksha Gehra, Shubhanshu Gupta. Outcomes of Visual Acuity after Paediatric Cataract Surgery at Medical College in Jhansi, (U.P) IOSR Journal of Dental and Medical Sciences (IOSRJDMS) Volume 15,Issue 5 Ver.IX (May.2016),PP54-58

\section{How to cite this article?}

Verma A, Jain P. Congenital cataract- a riddle to be solved to prevent childhood blindness. Trop J Ophthalmol Otolaryngol.2019;4(1):1-6.doi:10.17511/jooo.2019.i01.01 